\title{
Techno-Economic Analysis of an Improved Process for Producing Saturated Branched-Chain Fatty Acids
}

\author{
Helen L. Ngo ${ }^{1}$, Winnie C. Yee ${ }^{1}$, Andrew J. McAloon ${ }^{1} \&$ Michael J. Haas ${ }^{1}$ \\ ${ }^{1}$ USDA, ARS, Eastern Regional Research Center, Wyndmoor, Pennsylvania, USA \\ Correspondence: Helen L. Ngo, USDA, ARS, Eastern Regional Research Center, 600 E. Mermaid Lane, \\ Wyndmoor, Pennsylvania 19038, USA. Tel: 1-215-233-6643. E-mail: helen.ngo@ars.usda.gov
}

Received: February 24, 2014 Accepted: July 15, 2014 Online Published: September 15, 2014

doi:10.5539/jas.v6n10p158 URL: http://dx.doi.org/10.5539/jas.v6n10p158

Mention of trade names or commercial products in this article is solely for the purpose of providing specific information and does not imply recommendation or endorsement by the U.S. Department of Agriculture. USDA is an equal opportunity provider and employer.

\begin{abstract}
Methyl-branched fatty acids produced by isomerization of oleic acid ('isostearic' acids (IA)) are industrially useful products with excellent thermostabilities and lubricities and reduced freezing points relative to stearic acid. They have potential utility as biodiesel or a biodiesel additive imparting improved low temperature fluidity. We present a techno-economic model for industrial scale production of isostearic acid by zeolite-catalyzed isomerization. A catalyst regeneration loop allowing 20 reaction cycles was included. Use of catalyst for 15 or more reaction cycles reduced process cost by $51 \%$ vs. a single use reaction format. However, with a best-case predicted production cost of $\$ 2.375 / \mathrm{kg}(\$ 1.080 / \mathrm{lb})$, further process cost reductions will be required before use of IA esters as high percentage blend components of biodiesel is economically feasible.
\end{abstract}

Keywords: branched-chain fatty acids, ferrierite, isostearic acid, SuperPro Designer, techno-economic, zeolite

\section{Introduction}

The 2002 United States Farm Bill encouraged the use of biobased products; however, they must be economical, functional, and readily available (Schnepf, 2013). Biobased products can be derived from carbohydrates, proteins and lipids. Thus, they are generally more environmentally friendly materials and have lower toxicity when compared to petroleum-based materials. Fatty acid derivatives from fats and oils are being used in the biodiesel, lubricant, personal care, polymer, and surfactant industries. Although biobased products have many advantages over petroleum-based products, the high costs of some of the finished products have limited their adoption. To overcome this obstacle, research efforts to develop economically feasible technologies for the production of biobased materials are necessary, and these technologies and the products they generate must be competitive with or superior to petroleum-based processes and products.

Branched-chain fatty acids such as commercial isostearic acid (IA) are unique chemicals because of their novel and interesting properties (Ngo, Dunn, Sharma, \& Foglia, 2011). They are found in minor amounts in nature and are produced by industry in bulk quantities (Anderson \& Chargaff, 1929; Hayes, 1988). IA is a family of 17-carbon straight chain fatty acids containing a methyl group at any of various positions of the alkyl chain backbone (Figure 1) (Polgar, 1970). Steric consequences of the methyl branch cause reductions in the melting point of the fatty acid, yielding a potential biodiesel feedstock or lubricant with improved low temperature performance relative to the unbranched parent compound. Thus IA and their derivatives are used in applications such as body washes, coatings, cosmetics, lubricant additives, hydraulic fluids, and emulsifiers (Townend et al., 2012; Benoit, 1963; Sayad, 1967; Landfried \& Bassett, 1970). They have potential utility as low temperature compatible biodiesels or biodiesel additives. CRODA Co. currently manufactures IA under the trade name Prisorine $^{\mathrm{TM}}$ (P3505 ISAC) and Arizona Chemical, another leading oleochemical company, produces IA under the trade names Century ${ }^{\mathrm{TM}} 1105$ and 1107. 


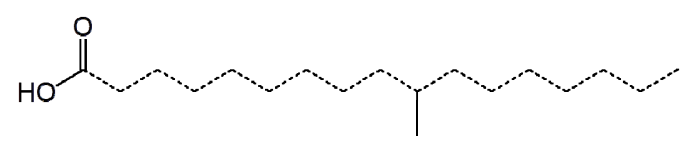

Figure 1. Isostearic acid

Dashed lines indicate several possible positions for the branching methyl group.

The existing technology for IA production involves clay-catalyzed oligomerization of tall oil fatty acid (Hayes, 1988). This process involves reactions with small amounts of water performed in stainless steel reactors at high temperature $\left(180-260{ }^{\circ} \mathrm{C}\right.$ ) and pressure (up to 10 bars). Generally, this reaction results in the formation of a mixture of monomeric (10-40\% saturated and unsaturated branched-chain fatty acids) and predominantly oligomeric (60-80\% $\mathrm{C}_{36}$-dimer fatty acids) species (Hayes, 1988). Dimer fatty acids have two carboxylic groups and an alkyl chain in an open or cyclic form. The exact compositions of dimer fatty acids depend on the catalysts and feedstocks used for their production. The chemical structures, physical properties and yields for these two fractions are quite different, and as a result, they are typically sold in two different markets (Anonymous, 2006). IA are made in limited production capacity and sold in the relatively higher value markets mentioned above. The dimer products enter the polyamide sector, and are considered to be in oversupply. Their prices can be half that of IA.

The currently employed clay catalyst technology for IA production has two major drawbacks. First, the reaction gives predominantly oligomeric by-products (mainly dimers and trimers) and thus exhibits a rather low yield of IA. Second, there is no data to indicate that clay catalysts can be reused, leading to a costly process with a negative environmental impact due to the burden of disposing the catalysts. Thus, there exists a need for more efficient and renewable processes for the production of IA.

In order to improve on the existing clay-catalyzed technology, several parameters could be considered. First, the initial catalyst cost could be lowered; second, the catalyst efficiency could be improved; third, the catalyst could have good recycling ability with acceptable levels of retained activity after regeneration; fourth, the catalyst could be an easily recovered one; and finally, the value of the synthesized product could be improved over that currently produced. We have sought to develop technologies to meet these criteria.

We (Ngo et al., 2007, 2011, 2012) and others (Hodgson, 1996; Tomifuji et al., 1997; Zhang et al., 2003, 2004, 2005) have previously described a zeolite catalyzed isomerization process for producing IA which appears to be promising alternative approach to the current clay technology. To evaluate the economic feasibility of this new process, computer modeling software such as Superpro Designer (Intelligen Inc., Scotch Plains, NJ) and Aspen Plus (Aspen Technology Inc., Burlington, MA) are commonly used to predict the capital and operational costs of a technology. Superpro Designer is a highly valuable tool by which scientists and engineers can assess the economics, process development needs, and environmental impacts of a technology before committing to a full scale implementation and commercialization. These tools have been successfully applied to determine the economic costs and feasibilities in various technology areas, including biodiesel production from refined soybean (Haas et al., 2006), rapeseed (Abo El-Enin et al., 2013), and algal oils (Taylor, et al., 2013). We have previously used this software to model H-Ferrierite zeolite catalyzed branching of oleic acid to produce IA (Ngo et al., , 2012). This model (Model 1) employed a catalyst regeneration technology that allowed catalyst to be reused for a total of at least 5 reaction cycles (Ngo et al., 2012). It predicted that the process could have significant positive impact on the economics of branched-chain fatty acid production, and the fact that the catalyst was recyclable greatly influenced the economics of the overall process (Ngo et al., 2012). Encouraged by this work, we have further refined the process, identifying an improved zeolite regeneration protocol that allows further reuse of the catalyst, potentially decreasing capital costs and energy consumption. In this paper, modified catalyst regeneration protocols that add either acid or heat treatment steps to the process are presented. Four techno-economic models for the production of branched-chain fatty acid products from oleic acid are presented and discussed.

\section{Results and Discussion}

\subsection{Description of the Process Model}

The economic impact of saturated branched-chain fatty acid isomer production using various catalyst 
regeneration protocols was evaluated by the computer simulation software SuperPro Designer (version 8.5. build 6). Similar to the previously reported model (i.e., Model 1) (Ngo et al., 2012), this new model (i.e., Model 2) was designed to operate for 330 days per year, $24 \mathrm{~h}$ per day with a plant capacity of 4.5 million $\mathrm{kg} \mathrm{yr}^{-1}$ (10 million lb $\mathrm{yr}^{-1}$ ). Model 2 differed from Model 1 in that Model 2 is based on a protocol involving 20 cycles of use whereas the previous model included only 5 catalytic cycles of use. The flow diagram for Model 2 is shown in Figure 2 and detail descriptions of Figure 2 can be found in the previously reported publication (Ngo et al., 2012). All processes modeled here were assumed to operate continuously. Continuous reactors have advantages over batch reactors in terms of their greater amenability to automatic control and operation. They have better quality control of the product lines over the batch process, and they reduce labor costs and stabilize operating conditions.

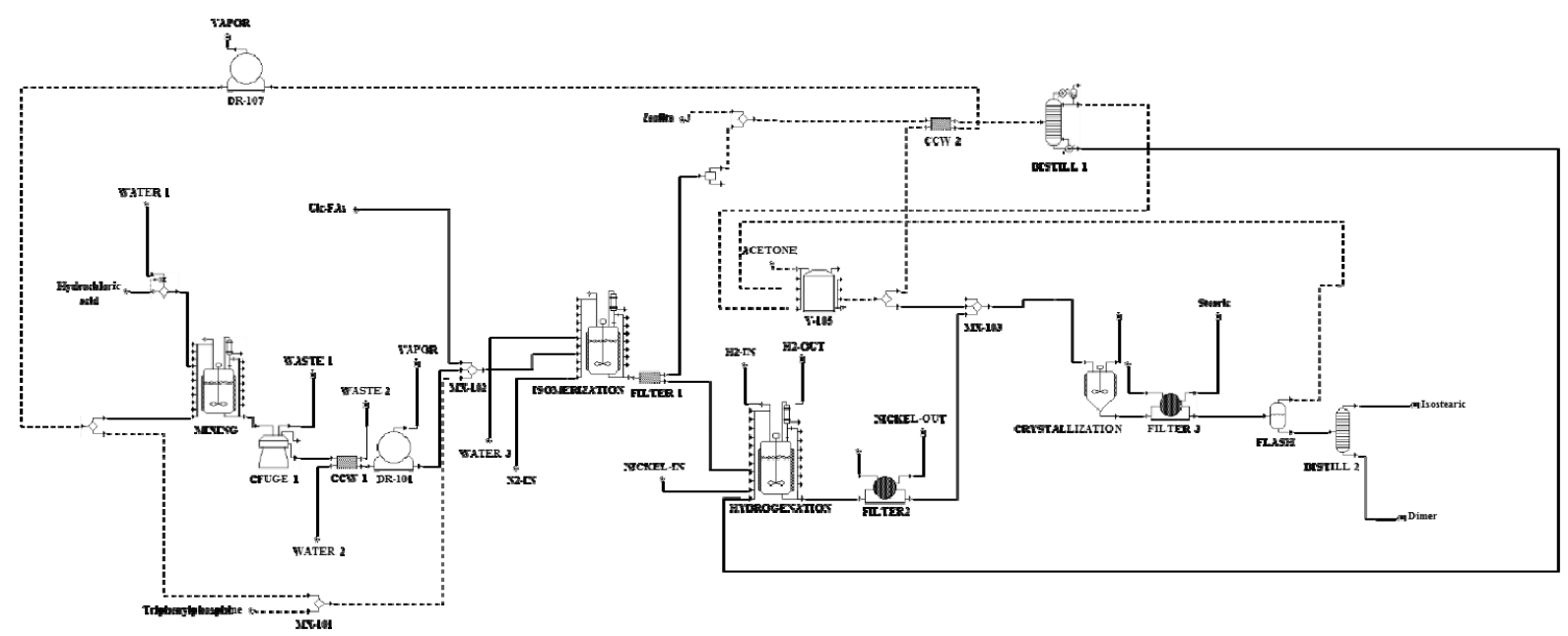

Figure 2. Flow diagram of isostearic acid technology

As in the previous model (Model 1) (Ngo et al., 2012), Model 2 was divided into three processing sections, namely (1) catalyst treatment and regeneration, (2) isomerization, and (3) product recovery. Dashed lines in Figure 2 identify new streams in the process relative to Model 1. By using an improved catalyst regeneration protocol, developed in our laboratory, we have shown that it is possible to use the catalyst at least 20 times without significant loss of catalytic activity. The ability of this catalyst regeneration protocol to allow retention of substantial catalyst activity and selectivity in multiple successive reactions is shown in Table 1. Detailed procedures for obtaining the experimental data were reported previously (Ngo, 2014). In Model 1, the branched-chain fatty acid product was produced by isomerization of oleic acid in the presence of catalytic amounts of H-Ferrierite zeolite and distilled water at $260{ }^{\circ} \mathrm{C}$ for $4 \mathrm{~h}$. After isomerization, the spent H-Ferrierite zeolite catalyst was recovered, washed with acetone to remove adsorbed lipid, dried, and regenerated by washing with dilute hydrochloric acid (Ngo, 2014). In Model 2, the catalyst was also recovered after isomerization, and acetone washed (Figure 2, CCW 2). Rather than proceeding to an acid wash step for regeneration, however, Model 2 implements a heat treatment step at this point $\left(115^{\circ} \mathrm{C}, 20 \mathrm{~h}\right.$, Figure 2, DR-107) since we recently determined that this treatment can routinely substitute for most acid washing steps. By the $5^{\text {th }}$ regeneration cycle, however, the catalyst shows a slight drop in activity (Table 1). We have found that an acid regeneration step at this point alleviates this activity loss, and thus an acid wash occurs in Model 2 after each five reaction cycles. 
Table 1. Ability of regeneration to restore/retain zeolite catalytic activity and selectivity in consecutive isomerizations of oleic acid to isostearic acid $^{\mathrm{a}}$

\begin{tabular}{ccccc}
\hline \multirow{2}{*}{ Entry } & Run & TPP $[\mathrm{wt} \%]$ & GC wt $\%$ & \multirow{2}{*}{ \% conversions ${ }^{\mathrm{b}}$} \\
\cline { 4 - 5 } & & & Isostearic acid & \\
\hline $1^{\mathrm{c}}$ & 1 & 7.5 & 82 & 99 \\
2 & 2 & 0 & 81 & 98 \\
3 & 3 & 0 & 80 & 98 \\
4 & 4 & 0 & 77 & 97 \\
5 & 5 & 0 & 75 & 93 \\
$6^{\mathrm{c}}$ & 6 & 2.5 & 84 & 99 \\
7 & 7 & 0 & 77 & 95 \\
8 & 8 & 0 & 78 & 97 \\
9 & 9 & 0 & 77 & 96 \\
10 & 10 & 0 & 75 & 93 \\
11 & 11 & 0 & 73 & 92 \\
$12^{\mathrm{c}}$ & 12 & 2.5 & 82 & 98 \\
13 & 13 & 0 & 81 & 98 \\
14 & 14 & 0 & 77 & 95 \\
15 & 15 & 0 & 70 & 89 \\
16 & 16 & 0 & 78 & 96 \\
17 & 17 & 0 & 75 & 95 \\
$18^{\mathrm{c}}$ & 18 & 2.5 & 80 & 98 \\
19 & 19 & 0 & 80 & 94 \\
20 & 20 & 0 & 80 & 94 \\
\hline
\end{tabular}

${ }^{\mathrm{a}} \mathrm{GC}$ data collected on the intact reaction product after isomerization, hydrogenation and methylation using methyl tridecanoate as internal standard. Reactions were carried with $5 \mathrm{wt} \% \mathrm{H}$-Ferrierite, TPP, $1.8 \mathrm{~mL}$ distilled water at $260^{\circ} \mathrm{C}$ for $4 \mathrm{~h}$.

${ }^{\mathrm{b}}$ Conversion calculated as $94.3-[($ methyl stearate -5.74$)] / 94.3 \times 100[94.3$ is the total unsaturated fatty acids in the starting fatty acids (oleic acid). 5.74 is the fatty acids in the oleic acid which do not contribute to the reaction].

${ }^{\mathrm{c}} \mathrm{Fresh}$ and spent zeolite catalysts were treated with dilute $\mathrm{HCl}$ acid solution in the presence of TPP.

Note: TPP=Triphenylphosphine.

In addition, in Model 2 as opposed to the previous model, each acid wash is followed by the addition of triphenylphosphine (TPP) to the subsequent isomerization reaction. The TPP treatment was added since we have recently learned that the addition of a small amount of TPP (2.5 to $7.5 \mathrm{wt} \%$ to zeolite catalyst) to the isomerization reaction suppresses the formation of dimer fatty acid product (Ngo, 2014), thus boosting isostearic acid yields (Table 2). The acid wash strips some TPP from the catalyst (data not shown), necessitating this TPP addition after each wash (Figure 2, MX-101). The heat and acid-TPP treatments can be repeated in multiple cycles (Table 1), a feature embodied in Model 2 to achieve a total of 20 uses of catalyst. 
Table 2. Product yields derived from the process model

\begin{tabular}{|c|c|c|c|c|}
\hline & \multicolumn{2}{|c|}{ Model $1^{\mathrm{a}}$} & \multicolumn{2}{|c|}{ Model $2^{b}$} \\
\hline & Flow Rate $\left(\mathrm{kg} \mathrm{yr}^{-1}\right)$ & Yield (\%) & Flow Rate $\left(\mathrm{kg} \mathrm{yr}^{-1}\right)$ & Yield (\%) \\
\hline \multicolumn{5}{|l|}{ Input } \\
\hline oleic acid (91.2 wt\% $\mathrm{C} 18: 1)$ & $5,628,796$ & --- & $5,628,796$ & --- \\
\hline \multicolumn{5}{|l|}{$\underline{\text { Output }}$} \\
\hline isostearic acid & $4,529,317$ & 78.6 & $5,089,626$ & 86.2 \\
\hline stearic acid & 476,253 & 8.30 & 574,429 & 9.73 \\
\hline dimer FAs & 752,069 & 13.1 & 238,103 & 4.07 \\
\hline Total & $5,757,639$ & 100 & $5,902,158$ & 100 \\
\hline
\end{tabular}

${ }^{a}$ Model 1 is a model previously reported in Ngo et al. (2012).

${ }^{\mathrm{b}}$ Model 2 is the new improved model reported here.

The acetone recovered from the catalyst wash step was purified by distillation (Figure 2, DISTILL1). Acetone from the distillation column and the flash tank, (Figure 2, FLASH) was collected in Tank V-105 (Figure 2) and redistributed for use in the catalyst washing and product recrystallization steps. Since the initial products are unsaturated and the item of commerce is saturated, hydrogenation of the initial product is necessary (Figure 2, HYDROGENATION). A small amount of residual fatty acids from the distillation column was recycled back to the hydrogenation reactor. Detailed descriptions of the hydrogenation reaction and the product isolation operations can be found in Model 1 (Ngo et al., 2012).

\subsection{Plant Operation and Analysis}

As indicated in Table 2, Model 2, for this industrial scale model the oleic acid input was 5,628,796 kg $(12,405,866 \mathrm{lb})$ and the outputs for the three products were $5,089,626 \mathrm{~kg}(11,217,535, \mathrm{lb}) \mathrm{of}$ IA, $574,429 \mathrm{~kg}$ $(1,266,041 \mathrm{lb})$ of saturated linear-chain fatty acid, and $238,103 \mathrm{~kg}(524,779 \mathrm{lb})$ of dimer fatty acids. To evaluate the productivity gain of Model 2, the productivity was expressed in terms of the total amount of product (kg) obtained per $\mathrm{kg}$ catalyst employed for Models 1 and 2 . The results showed a productivity gain of $105 \%$ from Model $1(204.6 \mathrm{~kg} / \mathrm{kg})$ to Model $2(419.5 \mathrm{~kg} / \mathrm{kg})$. This improved process of Model 2 generates a much larger amount of branched-chain fatty acid product and a substantially smaller amount of dimer product than achieved with Model 1 due to the use of TPP after each acid wash, as described above.

Table 3 lists the capital costs of Models 1 and 2. Capital costs were based on an engineering factored estimate developed from the costs of the individual equipment items necessary for the process. An additional allowance of $15 \%$ was added to these equipment costs to cover the processing equipment items that could not be defined at this time but would be required for the process. The total capital cost was then generated from these equipment prices by using a capital cost to equipment ratio of 3 to cover all other costs of construction materials and installation, engineering, and other charges associated with the construction of an industrial facility (Table 3 ). There was a slight increase in capital cost for the improved process of Model 2 because of the additional equipment needed for the zeolite treatment and regeneration. The costs of the other steps (i.e., isomerization, hydrogenation, product recovery) also went up slightly because of the larger tanks needed for this facility when compared to the Model 1 facility. Overall, the capital cost of the Model 2 process is approximately 3\% greater than that of Model 1, which is minimal given that this is calculated on a 10 year depreciation basis. 
Table 3. Predicted isomerization facility capital costs of the improved model

\begin{tabular}{|c|c|c|c|c|}
\hline & \multicolumn{2}{|c|}{ Model $1^{\mathrm{a}}$} & \multicolumn{2}{|c|}{ Model $2^{b}$} \\
\hline & $\begin{array}{c}\text { Equipment cost } \\
\text { (\$) }\end{array}$ & $\begin{array}{l}\text { Capital Cost } \\
(\$)^{\mathrm{c}}\end{array}$ & $\begin{array}{c}\text { Equipment cost } \\
\text { (\$) }\end{array}$ & $\begin{array}{c}\text { Capital Cost } \\
(\$)^{\mathrm{c}}\end{array}$ \\
\hline \multicolumn{5}{|l|}{ 1. Catalyst Treatment \& Regeneration } \\
\hline Hydrochloric acid handling \& storage & 34,000 & & 34,000 & \\
\hline Make up zeolite handling \& storage & 35,000 & & 35,000 & \\
\hline Zeolite activation & 68,000 & & 36,000 & \\
\hline Zeolite filtering \& centrifugation & 124,000 & & 124,000 & \\
\hline Zeolite drying & 46,000 & & 92,000 & \\
\hline Unlisted equipment for the zeolite area & 53,000 & & 56,000 & \\
\hline Catalyst treatment area total & 360,000 & $1,080,000$ & 377,000 & $1,131,000$ \\
\hline \multicolumn{5}{|l|}{ 2. Isomerization \& Hydrogenation } \\
\hline Oleic acid storage \& handling & 65,000 & & 66,000 & \\
\hline Isomerization reactor & 429,000 & & 437,000 & \\
\hline Zeolite separation & 48,000 & & 48,000 & \\
\hline Nickel catalyst storage \& handling & 35,000 & & 35,000 & \\
\hline Hydrogenation reactor & 50,000 & & 50,000 & \\
\hline Catalyst \& vapor removal & 59,000 & & 60,000 & \\
\hline Unlisted equipment for isomerization area & 119,000 & & 121,000 & \\
\hline Isomerization \& Hydrogenation area total & 805,000 & $2,416,000$ & 817,000 & $2,451,000$ \\
\hline \multicolumn{5}{|l|}{ 3. Product recovery } \\
\hline Acetone storage \& handling & 34,000 & & 34,000 & \\
\hline Recrystallization reactor & 394,000 & & 400,000 & \\
\hline Stearic separation \& storage & 147,000 & & 119,000 & \\
\hline Acetone recovery & 272,000 & & 333,000 & \\
\hline Isostearic/dimer distillation column & 53,000 & & 56,000 & \\
\hline Isostearic storage \& handling & 34,000 & & 34,000 & \\
\hline Dimer storage \& handling & 34,000 & & 34,000 & \\
\hline Unlisted equipment for product recovery area & 168,000 & & 175,000 & \\
\hline Product recovery area total & $1,136,000$ & $3,409,000$ & $1,185,000$ & $3,555,000$ \\
\hline Total system cost & $2,301,000$ & $6,905,000$ & $2,379,000$ & $7,137,000$ \\
\hline
\end{tabular}

${ }^{\mathrm{a}}$ Model 1 is a model previously reported in Ngo et al. (2012).

${ }^{\mathrm{b}}$ Model 2 is the new improved model incorporating 20 reuses of the catalyst.

${ }^{\mathrm{c}}$ Capital cost is generated from the equipment prices by using a capital cost to equipment ratio of 3 to cover all other costs of construction materials and installation, engineering, and other charges associated with the construction of an industrial facility.

Table 4 lists the annual operating costs, which includes material, utility, labor, and facility expenses for the two models. As shown, there is a significant saving with the new model because of the decrease in catalyst cost from Model 1 to 2 due to catalyst regeneration (i.e., $10.6 \%$ to 5.5\%). However, there are minor aspects which cause the unit production cost to go up, such as excess acetone and TPP employed in catalyst regeneration. Overall, 
Model 2 has a predicted unit product cost that is $\$ 0.16 \mathrm{~kg}^{-1}\left(\$ 0.07 \mathrm{lb}^{-1}\right)$ less than for Model 1. This is equivalent to a substantial savings of about $\$ 575,000$ annually. These results clearly show the importance of catalyst efficiency and recyclability.

Table 4. Predicted annual operating costs of Models 1 and 2

\begin{tabular}{|c|c|c|c|c|c|}
\hline \multirow{2}{*}{$\begin{array}{l}\text { Annual operating cost } \\
\text { summary }\end{array}$} & \multicolumn{2}{|c|}{ Model $1^{\mathrm{a}}$} & \multicolumn{2}{|c|}{ Model $2^{\mathrm{b}}$} & \multirow{2}{*}{$\begin{array}{c}\begin{array}{c}\text { Difference between } \\
\text { two models }\end{array} \\
\text { Annual cost }(\$)\end{array}$} \\
\hline & $\begin{array}{l}\text { Annual } \\
\text { cost }(\$)\end{array}$ & $\begin{array}{c}\text { Annual cost } \\
(\%)\end{array}$ & $\begin{array}{l}\text { Annual cost } \\
(\$)\end{array}$ & $\begin{array}{c}\text { Annual cost } \\
(\%)\end{array}$ & \\
\hline \multicolumn{6}{|l|}{$\underline{\text { Material Costs }}$} \\
\hline oleic acid (91.2 wt\%) & $9,344,000$ & 64.0 & $9,344,000$ & 66.7 & 0 \\
\hline zeolite ferrierite & $1,548,000$ & 10.6 & 774,000 & 5.5 & 774,000 \\
\hline nickel on silica & 862,000 & 5.9 & 862,000 & 6.2 & 0 \\
\hline acetone & 400,000 & 2.7 & 496,000 & 3.5 & $(96,000)$ \\
\hline triphenylphosphine & 0 & 0 & 19,000 & 0.1 & $(19,000)$ \\
\hline other raw materials & 164,000 & 1.1 & 174,000 & 1.2 & $(10,000)$ \\
\hline \multicolumn{6}{|l|}{$\underline{\text { Utilities }}$} \\
\hline electricity & 123,000 & 0.8 & 137,000 & 1.0 & $(14,000)$ \\
\hline steam & 261,000 & 1.8 & 280,000 & 2.0 & $(19,000)$ \\
\hline cooling agents & 92,000 & 0.6 & 102,000 & 0.7 & $(10,000)$ \\
\hline \multicolumn{6}{|l|}{$\underline{\text { Labor }}$} \\
\hline 2 operators / shift & 792,000 & 5.4 & 792,000 & 5.7 & 0 \\
\hline Facility Expenses & & 0 & & & 0 \\
\hline depreciation & 691,000 & 4.7 & 712,000 & 5.1 & $(21,000)$ \\
\hline other facility expenses & 314,000 & 2.2 & 324,000 & 2.3 & $(10,000)$ \\
\hline Total & $14,591,000$ & 100 & $14,016,000$ & 100 & 575,000 \\
\hline
\end{tabular}

${ }^{a}$ Model 1 is a model previously reported in Ngo et al. (2012).

${ }^{\mathrm{b}}$ Model 2 is the new improved model incorporating 20 reuses of the catalyst.

To explore the possibility of further reducing the cost of zeolite-catalyzed IA production, three additional process models (i.e., Models 3, 4 \& 5, Table 5) were developed, based on Model 2. These differ from the parent model in lacking certain process steps, in an attempt to evaluate the potential savings to be gained from their elimination.

Model 3 is similar to Model 2 except that a dryer (Figure 2, DR-107) has been removed from the process just downstream of the acetone washing of the catalyst during regeneration. It served to dry the catalyst with a treatment of $115^{\circ} \mathrm{C}$ for $20 \mathrm{~h}$. The unit production cost for IA synthesis by the process of Model 3 was $\$ 0.008$ $\mathrm{kg}^{-1}\left(\$ 0.004 \mathrm{lb}^{-1}\right)$ less than that for Model 2. Thus, there is little financial motivation to explore eliminating the catalyst drying step from the process. 
Table 5. Predicted annual operating costs of various catalyst treatment method studies

\begin{tabular}{|c|c|c|c|c|c|c|c|c|}
\hline \multirow{2}{*}{$\begin{array}{c}\text { Annual operating cost summary } \\
\text { Material Costs }\end{array}$} & \multicolumn{2}{|c|}{ Model $2^{\mathrm{a}}$} & \multicolumn{2}{|c|}{ Model $3^{\mathrm{b}}$} & \multicolumn{2}{|c|}{ Model $4^{\mathrm{c}}$} & \multicolumn{2}{|c|}{ Model $5^{\mathrm{d}}$} \\
\hline & $\begin{array}{l}\text { Annual } \\
\text { cost }(\$)\end{array}$ & $\begin{array}{l}\text { Annual } \\
\text { cost (\%) }\end{array}$ & $\begin{array}{l}\text { Annual } \\
\operatorname{cost}(\$)\end{array}$ & $\begin{array}{l}\text { Annual } \\
\text { cost }(\%)\end{array}$ & $\begin{array}{l}\text { Annual } \\
\operatorname{cost}(\$)\end{array}$ & $\begin{array}{l}\text { Annual } \\
\operatorname{cost}(\%)\end{array}$ & $\begin{array}{l}\text { Annual } \\
\text { cost }(\$)\end{array}$ & $\begin{array}{l}\text { Annual } \\
\text { cost (\%) }\end{array}$ \\
\hline oleic acid (91.2 wt\%) & $9,344,000$ & 66.7 & $9,344,000$ & 66.9 & $9,344,000$ & 65.6 & $9,344,000$ & 66.6 \\
\hline zeolite ferrierite & 774,000 & 5.5 & 774,000 & 5.5 & 774,000 & 5.4 & 774,000 & 5.5 \\
\hline nickel on silica & 862,000 & 6.2 & 862,000 & 6.2 & 862,000 & 6.1 & 862,000 & 6.1 \\
\hline acetone & 496,000 & 3.5 & 474,000 & 3.4 & 507,000 & 3.6 & 498,000 & 3.6 \\
\hline triphenylphosphine & 19,000 & 0.1 & 19,000 & 0.1 & 187,000 & 1.3 & 19,000 & 0.1 \\
\hline other raw materials & 174,000 & 1.2 & 175,000 & 1.3 & 178,000 & 1.3 & 174,000 & 1.2 \\
\hline$\underline{\text { Utilities }}$ & & & & & & 0.0 & & \\
\hline electricity & 137,000 & 1.0 & 137,000 & 1.0 & 141,000 & 1.0 & 138,000 & 1.0 \\
\hline steam & 280,000 & 2.0 & 278,000 & 2.0 & 284,000 & 2.0 & 281,000 & 2.0 \\
\hline cooling agents & 102,000 & 0.7 & 102,000 & 0.7 & 101,000 & 0.7 & 103,000 & 0.7 \\
\hline$\underline{\text { Labor }}$ & & & & & & & & 0.0 \\
\hline 2 operators / shift & 792,000 & 5.7 & 792,000 & 5.7 & 792,000 & 5.6 & 792,000 & 5.6 \\
\hline \multicolumn{9}{|l|}{$\underline{\text { Facility Expenses }}$} \\
\hline depreciation & 712,000 & 5.1 & 697,000 & 5.0 & 735,000 & 5.2 & 712,000 & 5.1 \\
\hline other facility expenses & 324,000 & 2.3 & 317,000 & 2.3 & 335,000 & 2.4 & 324,000 & 2.3 \\
\hline Total & $14,016,000$ & 100 & $13,971,000$ & 100 & $14,240,000$ & 100 & $14,021,000$ & 100 \\
\hline
\end{tabular}

${ }^{a}$ Model 2 is the new improved process, involving 20 catalyst reuses with regeneration by heat treatment $\left(115^{\circ} \mathrm{C}, 20 \mathrm{~h}\right)$ after each use and dilute $\mathrm{HCl} / \mathrm{TPP}$ treatment $\left(55^{\circ} \mathrm{C}, 24 \mathrm{~h}\right)$ after every $5^{\text {th }}$ use.

${ }^{\mathrm{b}}$ Model 3 is a variant of Model 2 implementing 20 catalyst use cycles without drying after solvent washing.

${ }^{\mathrm{c}}$ Model 4 is a variant of Model 2 implementing 20 catalyst use cycles, with acid treatment and $5 \mathrm{wt} \%$ TPP added followed by heat treatment at $115^{\circ} \mathrm{C}$ for $20 \mathrm{~h}$ after each use.

${ }^{\mathrm{d}}$ Model 5 is a variant of Model 2 implementing 20 catalyst use cycles with heat treatment at $260{ }^{\circ} \mathrm{C}$ for $4 \mathrm{~h}$ instead of $115^{\circ} \mathrm{C}$ for $20 \mathrm{~h}$ after each.

In Model 4 the catalyst was regenerated with acid and $5 \mathrm{wt} \%$ TPP after each use rather than heat. Due to additional reagent costs of TPP, the unit production cost for this model was $\$ 2.416 \mathrm{~kg}^{-1}\left(\$ 1.096 \mathrm{lb}^{-1}\right)$, an increase of $\$ 0.041 \mathrm{~kg}^{-1}\left(\$ 0.019 \mathrm{lb}^{-1}\right)$ compared to Model 2. This is attributable to the resulting net higher consumption of TPP used in the process, as shown in Table 5. This emphasizes the greater economy of using heat regeneration (Model 2) rather than acid-TPP (Model 4) when possible.

In Model 5 the effect of using an alternate heat treatment of the catalyst, with heating at $260{ }^{\circ} \mathrm{C}$ for 4 hours instead of $115^{\circ} \mathrm{C}$ for 20 hours after each use, was explored. The higher temperature/shorter time regime was chosen because it is known that catalyst regeneration occurs at that temperature (data not shown) and it was postulated that the shorter time of treatment might reduce energy costs. However, the unit production cost for this model was $\$ 2.376 \mathrm{~kg}^{-1}\left(\$ 1.078 \mathrm{lb}^{-1}\right)$, compared with $\$ 2.375 \mathrm{~kg}^{-1}\left(\$ 1.077 \mathrm{lb}^{-1}\right)$ for Model 2, an insignificant difference.

Using the techno-economic model a sensitivity study was conducted to evaluate the effect on IA production cost of implementing various degrees of catalyst reuse within the process. For a single-use process the model predicted an estimated unit production cost of $\$ 4.917 \mathrm{~kg}^{-1}\left(\$ 2.231 \mathrm{lb}^{-1}\right)$. As the extent of catalyst reuse increased the unit production cost decreased (Figure 3). The degree of this reduction was most pronounced over the course of the first five uses, being cut nearly in half in the 5-use model (i.e., $\$ 2.769 \mathrm{~kg}^{-1}\left(1.256 \mathrm{lb}^{-1}\right)$ ). With continued catalyst reuse the rate of cost reduction decreased substantially and the process cost essentially leveled off at $\$ 2.419 \mathrm{~kg}^{-1}\left(\$ 1.097 \mathrm{lb}^{-1}\right)$ at 15 uses. This indicates the point where the reduction in the cost of catalyst as a 
consequence of regeneration and reuse becomes insignificant compared to the total operating cost of the process.

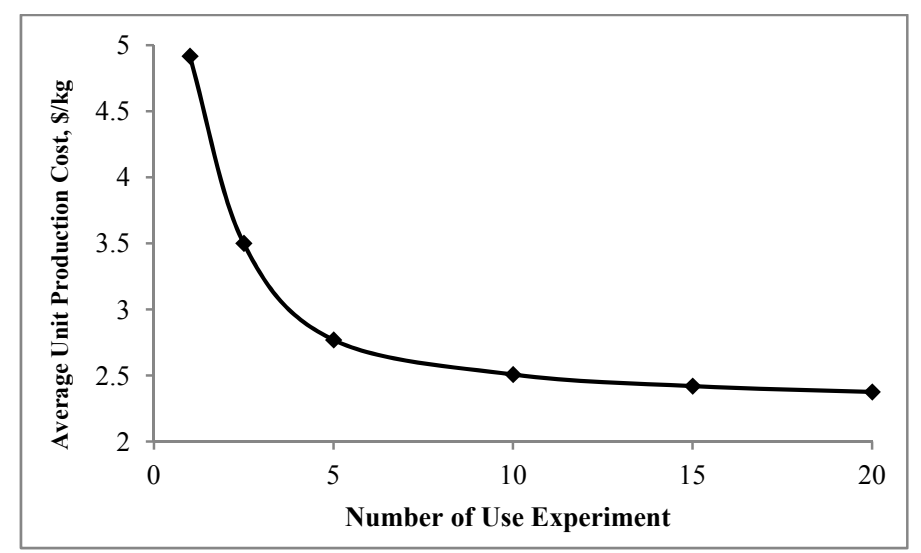

Figure 3. Impact of isomerization catalyst reuse on the unit production cost

\section{Conclusions}

There is a significant cost saving in the isostearic acid manufacturing process upon adopting the newly developed branched-chain zeolite technology. The high yields of the branched-chain product, the low formation of byproduct, and the facile catalyst regeneration protocols play significant roles in reducing the overall production costs. The process modeling studies here help identify the key areas that need to be improved and demonstrate the commercial viability of the technology. These modeling studies could help transition the developed branched-chain technology from research into industrial scale production and develop environmentally friendly and economically feasible engineering processes for other high-value biobased products. Thus, the skeletal isomerization approach for large scale production of biodegradable lubricants and hydraulic fluids could have both a positive environmental and industrial impact.

\section{Future Perspective}

Worsening global climatic conditions are likely to increase interest in the development of biobased replacements for today's petroleum-derived industrial products, be the fuels or nonfuels. In the context of biodiesel, poor low temperature fluidity is the single greatest property limiting its complete fungibility with the existing fuel pool. Thus, the development of biodiesel or biodiesel additives that improve the low temperature fluidity of biodiesel facilitate its adoption and will help ameliorate climate change. Similarly, development and adoption of other biobased industrial materials further fosters petroleum displacement. Isostearic acid can have uses in both fuel and nonfuel applications. Discovery of improved methods for their production will hasten their adoption. Development of techno-economic models to assess their production costs both allow quantitative assessment of these costs and help focus future research efforts to develop new technologies that reduce costs at the most expensive steps.

\section{Executive Summary}

- A techno-economic model constructed using laboratory-scale data for the industrial scale zeolite-catalyzed isomerization and subsequent hydrogenation of oleic acid to produce isostearic acid indicated a process cost of $\$ 4.917 \mathrm{~kg}^{-1}\left(\$ 2.231 \mathrm{lb}^{-1}\right)$ when the catalyst was discarded after a single reaction cycle.

- $\quad$ By implementing a catalyst regeneration technology developed in this laboratory a profound reduction in process cost was achieved.

- $\quad$ The minimum predicted IA production cost was $\$ 2.375 \mathrm{~kg}^{-1}\left(\$ 1.080 \mathrm{lb}^{-1}\right)$, attained upon use of the catalyst in 15 or more reaction cycles. This is a $51 \%$ reduction in cost relative to use of the catalyst in only one reaction.

- Substantial further cost reductions will be required to facilitate the use of e.g. methyl IA as a high percentage blend component to improve the low temperature fluidity of conventional biodiesel.

\section{Key Terms}

Isostearic acid: Traditional chemical name for the family of fatty acid positional isomers composed of a 17 carbon straight chain fatty acid backbone from which a single methyl group branch extends. Largely industrial 
products derived by isomerization and reduction of oleic acid (C18:1). The methyl branch is located at different positions of the carbon chain in the various isomers of the family, which are not generally available as pure species. These low-melting species display desirable lubricities and oxidative stabilities and are used in applications requiring these properties. Wider adoption is pending development of reduced-cost production technologies.

Ferrierite zeolite: Ferrierite zeolite is commercially available and has been used in the skeletal isomerization of butene to iso-butene. However, Ferrierite has not been previously examined for skeletal isomerization of fatty acids. It has 2-dimensional open channels of $5.4 \times 4.2 \AA$ formed by 10 -membered rings (10-MR) that are interconnected by smaller channels of $4.8 \times 3.5 \AA$ formed by 8-MR. The channels are ideal for enhancing the transport of oleic acid starting materials and isostearic acid products.

Techno-economic analysis/modeling: An approach to estimating the cost of a technological process, combining process modeling, engineering design and economic information to provide quantitative and qualitative assessments of capital and process costs. It is generally applied at industrial scales. In addition, its capability for sensitivity analysis allows this approach to identify process steps associated with highest costs, thereby allowing the efficient focus of research efforts on improving the economics of these steps.

\section{Acknowledgements}

We would like to thank NIFA-AFRI (grant award \# 2013-67021-21142) for providing partial funding support.

\section{References}

Abo El-Enin, S. A., Attia, N. K., El-Ibiari, N. N., El-Diwani, G. I., \& El-Khatib, K. M. (2013). In-situ transesterification of rapeseed and cost indicators for biodiesel production. Renewable and Sustainable Energy Reviews, 18, 471-477. http://dx.doi.org/10.1016/j.rser.2012.10.033

Anderson, R. J., \& Chargaff, E. (1929). The chemistry of the lipids of tubercle bacilli VI. Concerning tuberculostearic acid and phthioic acid from the acetone-soluble fat. J. Biol. Chem., 85, 77-88.

Anonymous. (2006). What is the global market outlook for polymerized fatty acid dimers and their monomer isostearic acid. Frost \& Sullivan Market Insight.

Benoit, G. J. Jr. (1963). US3110673.

Haas, M. J., McAloon, A. J., Yee, W. C., \& Foglia, T. A. (2006). A process model to estimate biodiesel production costs. Bioresour Technol., 97, 671-678. http://dx.doi.org/10.1016/j.biortech.2005.03.039

Hayes, K. S. (1988). US4776983.

Hodgson, W. R. (1996). EP0774451A1.

Landfried, B. W., \& Bassett, H. T. (1970). US3515562. Moneymaker JR.

Ngo, H. L. (2014). Improved zeolite regeneration processes for preparing saturated branched chain fatty acids. Eur. J. Lipid Sci. Technol., 116, 645-652. http://dx.doi.org/10.1002/ejlt.201300315

Ngo, H. L., \& Foglia, T. A. (2011). US2011/0263884 A1.

Ngo, H. L., Dunn, R. O., Sharma, B., \& Foglia, T. A. (2011). Synthesis and physical properties of isostearic acids and their esters. Eur. J. Lipid Sci. Technol., 113, 180-188. http://dx.doi.org/10.1002/ejlt.201000335

Ngo, H. L., Hoh, E., \& Foglia, T. A. (2012). Improved synthesis and characterization of saturated branched-chain fatty acid isomers. Eur. J. Lipid Sci. Technol., 114, 213-221. http://dx.doi.org/10.1002/ejlt.201000471

Ngo, H. L., Nunez, A., Lin, W., \& Foglia, T. A. (2007). Zeolite catalyzed isomerization of oleic acid to branched-chain isomers. Eur. J. Lipid Sci. Technol., 108, 214-224. http://dx.doi.org/10.1002/ejlt.200600246

Ngo, H. L., Yee, W. C., McAloon, A. J., \& Haas, M. J. (2012). Process and cost modeling of saturated branched-chain fatty acid isomer production. I\&EC Research., 51, 12041-12045.

Polgar, N. (1970). Natural alkyl-branched long-chain acids. In F. D. Gunsone (Ed.), Topics in Lipid Chemistry (Vol. 2, pp. 207-246). Logos Press Limited, London, UK.

Sayad, R. S. (1967). US3336225. McMahan AD.

Schnepf, R. (2013). Renewable Energy Programs and the Farm Bill: Status and Issues. Congressional Research Service.

Taylor, B., Xiao, N., Sikorski, J., Yong, M., Harris, T., Helme, T., Kraft, M. (2013). Techno-economic assessment of carbon-negative algal biodiesel for transport solutions. Applied Energy, 106, 262-274. 
http://dx.doi.org/10.1016/j.apenergy.2013.01.065

Tomifuji, T., Abe, H., Matsumura, Y., \& Sakuma, Y. (1997). US5677473.

Townend, J. D., Latus, J., Mccoy, P. J., Maltby, A. J., \& Parker, D. A. (2012). EP 2445865 A2. Slip and antiblocking agent.

Zhang, S., Zhang, Z., \& Steichen, D. (2003). US20030191330.

Zhang, S., Zhang, Z., \& Steichen, D. (2005). US6946567.

Zhang, Z., Dery, M., Zhang, S., \& Steichen, D. (2004). New process for the production of branched-chain fatty acids. J. Surf Detergents, 7, 211-215. http://dx.doi.org/10.1007/s11743-004-0306-x

\section{Copyrights}

Copyright for this article is retained by the author(s), with first publication rights granted to the journal.

This is an open-access article distributed under the terms and conditions of the Creative Commons Attribution license (http://creativecommons.org/licenses/by/3.0/). 